\title{
Show Me the Money
}

\section{The importance of network effects for mobile application business models}

\author{
Caren Crowley, Sam Michiels, Wouter Joosen \\ IBBT-DistriNet, Department of Computer Science \\ KU Leuven, Heverlee, B-3001, Belgium \\ caren.crowley@cs.kuleuven.be
}

\begin{abstract}
Recent years have seen a fundamental shift in the way that mobile applications are delivered to users. Developers are increasingly moving away from custom deployment approaches towards the use of platform markets for advertising and distributing their applications. Application developers use the platform to manage distribution and payment for applications. In return the application developer pays either a fixed and/or variable fee to the platform provider. Platform providers benefit from the availability of quality applications necessary to attract and retain end users to the platform. In this paper we present results from an original survey. We find that overall willingness to pay for applications remain low consumers are willing to pay for key apps which are perceived to significantly enhance everyday life. We then discuss opportunities for developers to increase cooperation with platform providers in order to enhance value creation, value delivery and value capture.
\end{abstract}

Keywords - Platform Markets; Mobile Applications; Network Effects.

\section{INTRODUCTION}

Despite the importance of mobile applications few studies have examined the importance of developing profitable business models for mobile application developers. Mobile applications are a key component of the mobile platform ecosystem, however mobile application developers are still struggling to find the right business model in order to profit from their innovation. Platform markets consist of one or more platforms acting as an intermediary between a network of supply-side and demand-side users [1,2]. Gawer and Cusamano [3] argue that platform leadership represents a distinct competitive strategy involving control of a central system around which other companies may develop a range of complementary technologies and products. Within this ecosystem the platform is the dominant player however the platform is dependent on the quality of available complements to develop a competitive advantage over rivals.

The most well known mobile platform ecosystem is undoubtedly that developed by Apple, composed of (a) the iPhone platform, (b) supply side users in the form of application developers and (c) demand side consumers who use the iPhone platform both on its own and to run various applications. Application developers use the platform to manage distribution and payment for applications. In return the application developer pays either a fixed and/or variable fee to the platform provider. This allows developers to concentrate on core competencies in terms of software development, while minimising business issues relating to the sale of the application. Demand-side users are then provided with easy access to a large number of applications, which increases the benefits of platform increasing the attraction and retention of end users.

A key distinguishing feature of platform markets is the presence of network effects between end users [4, 5]. Network effects are significant when certain products have little value when used on their own, however their benefit increases as other end-users avail of the service or technology [4]. Direct network effects occur between members of the same user group, i.e. supply side application developers or demand side application consumers. For instance, iPhone users experiences direct network effects if they derive a greater benefit from using the platform when their acquaintances also use the same product. Indirect network effects occur when users on opposite sides of the platform (both supply side and demand side users) derive a higher benefit from interacting with the platform the greater the number of users from the opposite side of the platform. Indirect network effects present a chicken and an egg problem. On the one hand a large number of applications attract demand side users to a platform. On the other hand, it is the size of the scale of demand-side users, which determines how many application developers are willing to join a given platform [6].

Indirect network effects are of primary importance for application developers as they derive a higher benefit from developing applications for platforms with a large installed user base with a greater number of consumers who may download their applications. Strong indirect network effects create barriers to entry leading to a limited number of dominant platforms within the industry. This can be clearly seen in the mobile market with a small number of dominant platform providers. The success of platform providers is closely tied to their ability to attract and retain high quality application developers. Industry analysts attribute the high quality of apps available to consumers as a key determinant of Apple's success [7]. The ability to offer high quality apps is likely to become more important to Apple and other platform providers as the difficulties in establishing intellectual property rights over existing hardware and technology become more pronounced. This can be clearly seen in the ongoing copyright war between Apple's iPad and the Samsung Galaxy 
Tablet [8]. As the number of platform providers increases providers are competing not only for end consumers of their technology but critically for access to high demand 'must have' applications. A central concern in developing business models in mobile markets is balancing the platforms providers desire for control and cooperation with network partners [8]. Application developers need to be mindful of this and seek to cultivate closer relationships with platform providers, which can prove mutually beneficial to both parties.

While prior work has focused on business models in mobile markets much of this work predates the development of third party apps and app stores $[10 ; 11]$. Drawing on work relating to business model development and network effects in two sided markets we present a discussion of key variables that need to be addressed. Section II reviews related literature on business models literature, in particular issues relating to value creation, value delivery and value capture. Section V concludes. Finally, Section VI discusses directions for future work.

\section{BUSINESS MODELS}

In order to profit from innovation, firms' need to excel not only in terms of product development but also in developing a viable and profitable business model. A business model involves implicit assumptions regarding customer behaviour, the actions of competitors and the costs and revenue opportunities available [10]. The business model of the firm determines how firms create, deliver and capture value [12].

Business-model innovation occurs when a firm adopts a novel approach to commercializing its underlying assets [13]. Technological innovation often leads to new innovative business models as such advances create 'both the need to bring new discoveries to market and the opportunity to satisfy previously unmet customer needs' [12]. In the case of mobile platforms, new entrants into the ecosystem in the form of application developers and continuing technological innovation has led to a need for business model innovation. Business model innovation is a necessity in mobile markets as much of the underlying technology did not exist or was not widely adopted until recently [14]. The widespread adoption of smartphones offers new and exciting opportunities for the development of mobile applications. In 2008 with Apple's introduction of the App Store, application developers supplying third party apps became a critical component of the mobile market ecosystem. The App Store generated significant excitement and forced other handset and OS manufacturers to try to reproduce similar dynamics and introduce their own app stores [14]. However a key impediment to the widespread development of high quality apps is the difficulty developers face in capturing the value from their applications. The availability of free applications developed by hobbyists has induced a low willingness to pay on the part of consumers. In order to develop a reliable revenue stream application developers need to become proactive and innovative in determining new ways to create, deliver and capture the value provided by their applications.

\section{A. Mobile Applications - Consumer Survey}

In order to better understand consumer's willingness to pay for mobile application we developed a short survey for smartphone users. The objective of the survey was to gain a general idea of smartphone usage, and in particular consumers willingness to pay for mobile applications. The survey was composed of three parts, (i) background information, (ii) application downloading behaviour (iii) application payment options. Due to time constraints a convenience sample was used involving members of the authors research group. While this sample is not representative of the general population, all respondents were computer scientists ranging from doctoral candidates to senior faculty. As such, these individual are expected to be ahead of the curve in terms of technology adoption. In total 73 email invites were sent out, with a single reminder email. 62 people completed the survey representing an $85 \%$ response rate. The median age of respondents is 29 with males representing $85 \%$ of respondents and females $15 \%$. In total $63 \%$ of respondents use a smartphone while $37 \%$ currently do not. Only smartphone users were asked to complete the mobile application usage questions.

\section{B. Value Creation.}

In order to develop viable business models application developers need to explicitly address how the application will create value for others? Value is always intangible, heterogeneously experienced, co-created, and potentially perishable [15]. Rogers [16] argues that in order for an innovation to be adopted it needs to be compatible with daily life and have a clearly visible advantage over similar products or services. In order to charge for apps, developers need to create value for the consumer which is significantly higher than that offered by free substitutes.

\section{1) Most used Apps}

'In the last week (previous 7 days) which type of apps did you actually use on your smartphone?'

Utility apps (45\%)

Entertainment apps (24\%)

Game apps (34\%)

News apps $(34 \%)$

Productivity apps (63\%)

Search tools $(40 \%)$

Social networking (31\%)

Sports apps $(10 \%)$

Travel apps (11\%)

Weather apps (21\%) 


\section{2) Most likely to pay for}

'Which type of apps would you be most likely to pay for?'

Utility apps (31\%)

Entertainment apps $(0 \%)$

Game apps (52\%)

News apps $(21 \%)$

Productivity apps (41\%)

Search tools $(10 \%)$

Social networking $(0 \%)$

Sports apps $(10 \%)$

Travel apps $(31 \%)$

Weather apps $(21 \%)$

Other $(13 \%)$

While certain apps are popular in terms of use there is low willingness to pay and an expectation that they should be freely available, for instance search tools or social networking apps. Productivity and utility apps stand out as being those that are most popular and individuals are also willing to pay for increased functionality. Building on insights we argue that customised apps offer greater opportunities for value creation than standardised apps which will in turn positively impact the consumers willingness to pay. Custom apps are context rich and use data gathered from the user to create an enhanced user experience. For instance, user location is an example of gathered data, which can be used to provide a more targeted end user experience. Location data can be used in targeted advertising campaigns, notifying the consumer of local attractions or special offers available nearby. Technology and service providers need to plan for a future of content and products and marketing strategies that deliver a much richer contextual experience for the consumer with opportunities for micro-targeting content and marketing messages [14]. We argue that data gathering can create value for the consumer beyond geographically relevant advertising. For example, users may be actively recruited as 'human sensors' [17] voluntarily inputting personal data into trusted apps in order to receive a higher value added service. Users tend not to be fully aware of their privacy exposure but technology and service providers face a negative consumer backlash if they fall short of consumer expectations. Most users will continue to look for higher value contextual services and be ready to trade-off some of their privacy to brands they trust in order to receive location specific services.

\section{Value Delivery.}

The value delivery component of the business model concerns how to communicate and deliver value to the end consumer. Key issue for application developers involve striking a balance between cooperation and competition with ecosystem members [ 7] and increasing awareness of their applications. We argue that application developers are likely to benefit from close and deep collaboration with platform providers, particularly those that are new entrants to the sector and likely to value the benefits of high quality applications. De Reuver and Bouwman [18] find that relationships between mobile service providers typically involve power based governance in the early states progressing to trust based governance during roll out and commercialisation. We argue that strong cooperative trust based relationships should be cultivated by both application developers and new entrant platforms. The platform provider benefits through the development of high quality applications, which will help to attract and retain end users and limit, churn (i.e. users joining and leaving the network). Platform providers need to understand the value provided by quality applications and foster the development of the ecosystem. When an application exhibits strong demand side network effects the application developer may be able to negotiate with the platform provider for a reduced platform access fee and/or additional functionality.

Application development is a long and costly process. Platform providers therefore need to develop relationships with supply side users more than a year before the platform is ready to go to market in order to ensure that enough application support will be available at launch [19]. As such, value delivery involving a 'sponsored' application whereby the platform provider acts as a sponsor providing both price and non-price subsidies to the developer may be especially valuable for both application developers and platform providers at the pre-launch or early platform development stage.

A price subsidy may involve a reduced or zero-price for platform access. On the other hand, a non-price subsidy from the platform to the application may involve (a) functionality that is useful to the application but not directly useful to the end user of the platform (b) functionality that gives additional value to the application over and above the value it adds to the platform and (c) functionality that reduces the costs or improves the performance of the application [23]. Sponsored applications have greater access to the resource of the platform provider and should be designed to develop, as must have applications, generating strong indirect network effects to attract demand side users to the platform. In such cases value is captured following the licensing of the application to the platform provider.

Support for the mutual benefits of sponsored applications can be seen by the importance of must have applications to consumers with almost one quarter of smartphone users stating that access to must have applications have influenced their choice smarthone and or operating system.

\section{1) Must have applications}

'Has your choice of smartphone and / or operating system been influenced by access to hot or 'must have' applications?'

Yes $24 \%$

No $76 \%$ 


\section{Value Capture.}

Developers continue to struggle to capture the value created by their applications. Hobbyists may be satisfied to release their applications for free and benefit from the perceived prestige; however, professional developers need to generate revenue to keep the business viable. Application developers operate in a market where the primary fixed cost is the labour of the developer while the marginal costs of production tend to zero, i.e. for every additional unit of the product sold the marginal costs are close to zero. Platforms often treat one user group as a loss leader, charging a zero or minimum price while the other group is the primary source of revenue. This is the rationale behind Apple's decision to only recoup a percentage of the fee charged for apps as opposed to a per-app fixed fee.

Business to customer payment involves a direct payment from the customer who downloads the app to the application developer and a corresponding percentage based payment from the application developer to the platform provider. In general however consumers have a low willingness to pay for apps and strategic pricing options may be employed to increase revenue with almost half of respondents stating that they had never paid to download an app.

\section{1) Free Apps}

'Of the apps which you have downloaded, approximately how many were free'?

$100 \%(45 \%)$

$90 \%(29 \%)$

$80 \%(5 \%)$

$70 \%(8 \%)$

$60 \%(3 \%)$

$50 \%(10 \%)$

$>40 \%(0 \%)$

Strategic pricing is a key attribute of platform markets as a result of the presence of network effects between end users. A strategic pricing strategy is beneficial as platform profit is dependent on both (a) promoting network effects due to clever product design and (b) correct choice of user group to subsidise. Strategic pricing refers to both the level and structure of pricing used to attract and retain supply side and demand side users. Pricing structure involves a choice between fixed and/or variable fee. A lump sum membership fee is charged when the influence of indirect network effects are low $[21,22]$. In this case the benefit of the platform for one user group is not dependent on how well the platform performs in attracting users from the opposite group. For instance in the case of newspapers demand side readers are not concerned about the ability of newspapers to attract supply side advertisers provided the overall price of the product is low. In such case it may be most profitable to charge a lump sum membership fee.
A variable use fee is preferable when indirect network effects are strong. As discussed previously in the case of mobile application the benefit of platform affiliation for demand side users is dependent on the availability of application developers. In addition, micro-payment is best when participation can be monitored at low cost and the implementation of micro-payment is not prohibitively expensive. In the case of iPhone apps, application developers pay $30 \%$ of the price to apple and retain $70 \%$. It is feasible to measure the number of downloads of each app. However, a per-use variable fee may be viewed as an opportunity cost. If an application developer can obtain a higher profit by distributing their application on an alternative platform they may choose and alternative platform provided that the switching costs are not prohibitively high. In addition variable use fees reduce the effects of indirect network effects as a portion of the benefit of the transaction is eroded as a consequence of the fee. In the case of platforms which have a dominant position in the market a per-use transaction fee is the de facto choice However, for new entry platforms innovative alternative to a fixed per use fee need to be explored. A membership fee negotiated between application developers and platform providers may then be an optimal strategy for both new entrants and application developers.

In addition app developers can leverage strategies such as subsidies, free trials and versioning to a much greater extent than vendors of conventional goods [23]. Appropriate business models for mobile applications need to convince users of the benefits of the product prior to charging a monetary fee. Katz and Shapiro [5] refer to an incumbent in an industry with high barriers to entry using penetration pricing to establish the technology. Such investments will later be recouped by pricing in excess of marginal cost. Potential consumers may be put off by an initial up front cost but may be willing to pay for additional services once they have benefitted from the service. Parker and Van Alstyne [24] offer two alternatives to a fixed fee to encourage platform usage while taking advantage of network effects. The network effects in this case are not between end users but between different points in time or user needs. Firstly, a free trial with temporal network effects between time 1 and time 2 . Users are subsidised in time 1 while charging a premium price in time 2 . The time invested in learning the command structure and capabilities of the application create switching costs relative to other applications and therefore encourage the user to pay. Secondly, paid upgrades with network effects between novice and pro users may be created. The novice version is distributed free of charge while an additional fee is charged for additional functionality or services. The less functional version encourages experimentation and purchase of the full version. In such cases the application is offered for free and then other premium services such as upgrades or additional services are offered at a cost. The fremium model is relatively well established but has been met with mixed results. Of the respondents surveyed approximately one quarter had paid a fee once the free trial had ended with the same proportion 
opting on at least one occasion to pay for increased functionality.

\section{2) Free trials}

'Of the apps on your phone did any of them involve a free trial period?'

No, I never download an app with a free trial (68\%)

Yes, I have downloaded apps with a free trial but I chose not to pay once the trial ended $(8 \%)$

Yes, I have downloaded apps with a free trial and on one or more occasion I have decided to pay (24\%)

\section{3) Paid upgrades}

'Of the apps currently on your phone do any of them involve paid upgrades?'

No, I never download an app with a paid upgrade (33\%)

Yes, I have downloaded an app with the possibility of a paid upgrade but I decided not to pay for additional functionality $(43 \%)$

Yes, I have downloaded an app with the possibility of a paid upgrade and I decided to pay for increased functionality on at least one occasion $(24 \%)$.

We argue however that the model is still viable when combined with other more innovative aspects of the business model, for instance customised application which creates enhanced value for the end user and/or sponsored applications which positively impact value delivery through increased exposure of key applications and lower costs for developers through both price and non-price mechanisms (increased functionality).

In addition to vertical selling to end-customers, platform providers may choose to sell horizontal in a business-tobusiness transaction. This is a common path for software developers who may concentrate on their core competency of software development, while outsourcing the monetization of their product. Developers can gain revenue by offering the application as a platform for third parties such as inapplication advertising or data gathering. Those applications, which produce strong positive indirect network effects, are likely to be adopted by a wide user group. Applications that are widely adopted can be used as platforms for in application advertising. The advertiser pays the developer based on the number of clicks via the application. Gartner anlysts predict that in mobile application will increase dramatically [14] however if advertisers are to benefit they need to develop innovative means of engaging the consurmers as respondents do not consciously pay attention to advertising campaigns.

\section{4) In-app Advertisements}

'Of the apps currently on your phone do any of them involve in-app advertisements?'
No, I prefer not to download apps with advertisements (32\%) Yes, some apps have advertisements but I generally ignore them $(65 \%)$

Yes, some apps have advertisements and I occasionally click on them or otherwise explore the product offering $(0 \%)$

Yes, some apps have advertisements but if its an app that I user regularly I pay to upgrade to the advert free version (3\%)

In addition applications may also be used to gather data, which is then sold onto a third party. For instance, a route-finding application which use GPS locational data may be accessed for free by end-users and in exchange the localization data may be aggregated and used by third parties to detect regions with slow moving traffic (i.e. traffic jams). In examining innovative approaches to value delivery we suggested the use of user data to develop customised, context rich applications. This data may also be used to capture value for the developer through partnerships with third parties. In terms of selling data to third parties caution is certainly required. At present users tend not to be fully aware of their privacy exposure, however technology and service providers face a negative consumer backlash if they fall short of consumer expectations [14]. It is expected however that most users will look for higher value contextual services and be ready to trade off some of their privacy to the brands they trust in order to receive location specific services [14].

\section{5) Data gathering}

'Of the apps currently on your smartphone do any of them involve in-application data gathering?'

No, none of the apps on my phone gather data but it would be ok if they did $(0 \%)$

No, none of the apps on my phone gather data, if they did I would delete the app (47\%)

Yes, I have some apps which gather data and that is ok with me $(17 \%)$.

I do not know $(36 \%)$

\section{CONCLUSIONS}

This paper has highlighted the need for greater discussion and exploration of viable business models for application developers. From this analysis, we highlight four key lessons for mobile application developers:

1. Mobile application developers should seek to cultivate strong trust based relationships with platform providers. In particular new entrants competing with dominant incumbent platform are most likely to be open to this strategy. Such cooperation is mutually beneficial due to the presence of both direct and indirect network effects amongst platform users.

2. In order to create enhanced value for customers 
developers should focus on developing context enriched, higher value added products for which consumers are willing to pay a premium provided the enhanced benefit is clearly communicated.

3. Increased cooperation between platform providers and mobile application developers will also enhance value delivery. Sponsored applications will have higher visibility and also increased functionality. The costs of increasing functionality should be split between both the platform provider and provider.

4. In deciding on a pricing strategy, application providers should move away from a fixed price for their applications and consider alternative business models such as fremium, third party or sponsored applications.

In addition to these concrete lessons, we identify that in general there is a significant lack of research into business models for mobile application developers compared to research in platform markets. We argue that the lack of focus on application developers, and in particular on business models for mobile application developers may leave developers asking: "where is the money?" and thus endanger the long-term development of contemporary platform marketplaces.

\section{FUTURE WORK}

This paper provides a first step in analyzing potential business models for mobile application developers drawing on the opportunities and challenges provided by network effects between end users. We now elaborate on promising avenues for further work:

Firstly, while current literature highlights the important role of network effects and strategic pricing, the specific impact of these factors on the characteristics of contemporary platform marketplaces has not been empirically investigated. A comparative study of contemporary mobile marketplaces for platforms such as Android, iPhone and Windows Phone, each of which have different network effects and pricing schemes would shed more light on the relationship between various platform characteristics and financial viability of platform marketplaces for application developers.

Secondly, significant new research is needed into business models for application developers working in platform marketplaces. In particular research is needed into strategies that can mitigate risk and maximize return for developers working in these highly competitive environments. Developing innovative applications requires the mastery of computer science and related skills. However discerning which product or service users will pay for requires idiosyncratic understanding of marketing relationships and sometimes even ethnographic investments to extract information about needs that may be as yet incompletely identified or articulated. This paper involved a short survey administered to a convenience sample. It is hoped that this survey will be expanded and send to a more representative sample which would involve both respondents in developed (Europe / USA) and emerging economies (China/ Brazil)

Finally, in-depth research is required into how platform developers can attract and maintain an optimal balance of supply-side users (i.e. application developers) and demandside users (i.e. application users). On the one hand, a large community of application developers is required to ensure that a sufficient supply of applications is available to attract users, while on the other hand; sufficient support must be provided to application developers to ensure that development of applications for platform markets remains an economically attractive prospect.

\section{REFERENCES}

[1] J. Rochet and J. Tirole, "Cooperation among competitors, some economics of paymnet card associations" Rand Journal of Economics, Vol. 33, 2002, pp. 549- 570

[2] T. Eisenmann, T. Parker and M. Alstyne, "Strategies for two sided markets", Harvard Busines Review, October, 2006 pp.1-10

[3] A. Gawer and M. Cusamano, "Platform leadership : how Intel, Microsoft, and Cisco drive industry innovation. Boston: Harvard Business School Press.

[4] M. Katz and C. Shapiro, "Technology adoption in the presence of network externalities", Journal of Political Economy, Vol. 94, 1986 pp.822-841

[5] M. Katz and C. Shapiro, "System competition and network effects" American Economic Association, Vol. 100, 2010, pp.1642-1675

[6] C. Hogendorn and S. Kayatyuen, "Platform competition with must-have components", The Journal of Industrial Economics, LVII, 2009, pp.294318

[7] MSNBC,

http://www.msnbc.msn.com/id/38382217/ns/technology_and_sciencewireless/t/app-showdown-android-vs-iphone/\#.UBbpfGjdt7Y, retrieved on 10-07-2012

[8] Irish Times, http://www.irishtimes.com/newspaper/breaking/2012/0709/breaking30.h tml, retrieved on 15-07-2012

[9] P. Ballon, "Business modelling revisted: the configuration of control and value", infor, Vol. 9, 2007, pp6-9

[10] A. Tsalgatidou and E. Pitoura, "Business models and transactions in mobile electronic commerce: requirements and properties" , 37, 2002 pp. 221-236

[11] C. Leem, H. Suh and D. Kim, "A classification of mobile business models and its applications", 104, 2004, pp78-87

[12] D. Teece, "Business models, business strategy and innoation, Long Range Planning, Vol. 43, pp.172-194

[13] A. Gambardella and A. McGahn, "Business-model innovation: general purpose technologies and their implications for industry structure, Long Range Planning Vol. 43 pp.262-271

[14] T. Nguyen "Hype cycle for mobile device technologies 2011", Gartner Group, Retreived 14-11-2012

[15] S. Vargo, P. Maglio and M. Akaka, "On value and value co-creation: a service systems and service logic perspective", European Management Journal, Vol. 26, 2008, pp.145-152

[16] E. Rogers "Diffusion of innovation" New York: the Free Press

[17] SENSORS

[18] M. De Reuver and H. Bouwman, "Governance mechanisms for mobile service innovation in value networks" Journal of Busienss Research, 65, 2012, pp347-354 
[19] A. Haigu, "Two-sided platforms: product variety and pricing structures" Journal of Economics and Management Strategy, Vol.18, 2009, pp.1011-1043

[20] N. Economides and E. Katsamakas "Two sided competion of proprietary vs open souce technology platforms and the implications for the software industry, Management Science Vol. 52, pp.1057-1071

[21] C. Hogendorn and S. Kayatyuen, "Platform competition with must-have components", The Journal of Industrial Economics, LVII, 2009, pp.294318
[22] M. Armstrong, "Competition in two-sided markets" Rand Journal of Economics, Vol. 37, 2006, pp668-691

[23] J. Gallagher and Y-M. Wang "Understanding network effects in software markets: eveidence from web server pricing", MIS Quarterly, Vol.26, 2002, pp. 303-327

[24] G. Parker and M. Alstyne, "Two sided network effects: a theory of information product design", Management Science, Vol.51, 2005, pp. $1494-150$ 